\title{
Validação do método de Ducos modificado para a determinação do ácido trans,trans-mucônico urinário
}

\author{
Flávia Cristina Silva de Paula, Josianne Nicácio Silveira, Edna Maria Alvarez-Leite
}

Laboratório de Toxicologia Ocupacional, Departamento de Análises Clínicas e Toxicológicas, Faculdade de Farmácia, Universidade Federal de Minas Gerais

*Correspondência:

F. C. S. de Paula

Rua D 40 Betânia

CEP 30590-060 - Belo Horizonte - MC Brasil

E-mail: depaulaflavia@ig.com.br
O presente trabalho foi realizado objetivando validar um método analítico para a determinação do ácido trans,trans-mucônico (ATTM) urinário empregando-se cromatografia líquida de alta eficiência com detecção UV. O ATTM foi previamente extraído das amostras biológicas, utilizando-se colunas de troca iônica e identificado por cromatografia líquida de alta eficiência (CLAE). O cromatógrafo foi equipado com coluna de fase reversa Lichrosorb RP 18, $5 \mu \mathrm{m}(250 \times 4,2 \mathrm{~mm})$. A temperatura da coluna foi mantida a $40{ }^{\circ} \mathrm{C}$. A fase móvel utilizada foi ácido acético $1 \%$ - metanol (90$10 \mathrm{v} / \mathrm{v}), \mathrm{pH}=2,72$ a um fluxo de $1 \mathrm{~mL} / \mathrm{min}$ e detecção $U V$ em comprimento de onda de $264 \mathrm{~nm}$. O método apresentou linearidade

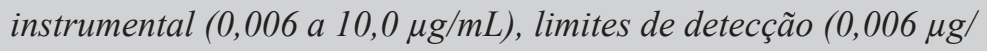
$\mathrm{mL}$ ) e quantificação $(0,03 \mu \mathrm{g} / \mathrm{mL})$, precisão (CV intra-ensaio: 9,57\%, CV interensaio: 11,15\%) e recuperação (86,45\%) adequados à determinação da concentração urinária de ATTM em trabalhadores expostos ao benzeno.
Unitermos:

- Ácido trans,trans-mucônico

- Benzeno

- Validação

- Cromatografia líquida de alta eficiência

- Biomonitorização

\section{INTRODUÇÃO}

Um novo conceito de controle da concentração de benzeno nos ambientes ocupacionais foi adotado, recentemente, no Brasil. Trata-se do Valor de Referência Tecnológico (VRT), que deve ser considerado como referência para os programas de melhoria contínua dos ambientes de trabalho. Os valores adotados para o VRT foram de 1,0 ppm para as indústrias químicas e petroquímicas e 2,5 ppm para as indústrias siderúrgicas (Brasil, 2001).

A diminuição dos limites de exposição ao benzeno desencadeou dificuldades relativas à monitorização biológica do trabalhador exposto. A determinação do fenol urinário, principal metabólito do benzeno, não apresenta sensibilidade para avaliar exposições inferiores a $10 \mathrm{ppm}$, uma vez que este composto apresenta valores basais elevados que podem alcançar até $20 \mathrm{mg} / \mathrm{g}$ de creatinina (Bechtold et al., 1993; Ducos et al., 1990).

Este fato levou a Secretaria de Segurança e Saúde no Trabalho do Ministério do Trabalho brasileiro (SSST-MTb) a suprimir, em 1994, o uso do fenol urinário como indicador biológico de exposição ao benzeno (Brasil, 1994).

Nos últimos anos, vêm-se desenvolvendo estudos objetivando avaliar e adotar novos biomarcadores e novas metodologias analíticas, que apresentem sensibilidade para avaliar a exposição ocupacional a baixas concentrações de benzeno (Bechotold et al., 1992, 1993 e 1996; Ong et al., 1995; Kivisto et al., 1997). 
Na lista de possíveis biomarcadores de exposição ao solvente, além do próprio agente inalterado em amostras biológicas, estão os metabólitos fenólicos (catecol, hidroquinona, benzenotriol), os metabólitos não-fenólicos (ácido trans,trans-mucônico - ATTM e ácido fenilmercaptúrico - AFM) e os compostos resultantes da ligação do benzeno epóxido ao DNA, RNA ou proteínas. Dentre eles, os mais sensíveis são o ATTM e o AFM urinários e o benzeno inalterado no sangue, ar exalado e urina.

O ATTM, embora tenha sido identificado como metabólito do benzeno desde o início do século XX, somente nos anos 80 foi proposto como biomarcador na monitorização de exposição ocupacional a baixos níveis deste composto (Ducos et al., 1990), pois apresenta correlação com o benzeno no ar quando os níveis ambientais do composto são iguais ou inferiores a 1,0 ppm (Ducos et al., 1990; Raucher et al., 1994; Lauwerys et al., 1994).

A sensibilidade, a simplicidade analítica da determinação do ATTM urinário, especialmente quando comparada com a determinação do AFM (Gad-El Karim et al., 1985; Ducos et al., 1990; Boogaard et al., 1995; ACGIH, 1999) e a melhor correlação entre ATTM e baixos níveis de benzeno (Ong et al., 1995), quando comparada com a correlação existente entre o fenol urinário e o solvente, são fatores que justificam o uso do ATTM como o indicador biológico de exposição ao benzeno (Ong et al., 1995).

A principal desvantagem do ATTM como biomarcador é o fato de sua concentração urinária ser influenciada por fatores e características individuais, como por exemplo o hábito de fumar e a dieta (Melikian et al., 1993, e 1996; Oga, 1996). Estudos realizados em indivíduos não expostos relatam valor de referência na faixa de $<0,01$ $0,66 \mathrm{mg} / \mathrm{g}$ de creatinina para o ATTM urinário (Boogaard, van Sitter,1995; Gobba et al., 1997) .

Para que este biomarcador possa ser adotado na monitorização de exposição ocupacional ao benzeno é necessário que se estabeleça, além do valor de referência e dos fatores que influem na concentração basal do ATTM, a correlação entre seus níveis urinários e a concentração de benzeno no ar, no momento da colheita da amostra biológica. Para tal, é necessário se dispor de um método de determinação do ATTM urinário que seja sensível, preciso, exato e simples.

Duas metodologias, igualmente sensíveis, têm sido descritas para a determinação de ATTM, a cromatografia em fase gasosa (CG) (Bechtold et al., 1991; Melikian et al., 1994) e a cromatografia líquida de alta eficiência (CLAE) (Gad-El Karim et al., 1985; Ducos et al., 1990).

A utilização da CG com detecção por espectrometria de emissão de massa (CG/MS) ou ionização em chama (CG/DIC) na determinação do ATTM urinário, requer além da etapa de pré-tratamento da amostra, para eliminar os possíveis interferentes presentes nessa matriz complexa, a derivatização do metabólito extraído para que o mesmo possa ser detectado pela cromatografia gasosa. Estas etapas contribuem para a diminuição na porcentagem de recuperação e na precisão dos métodos por CG (Scherer et al., 1998).

Os métodos que utilizam a CLAE são mais empregados atualmente, em decorrência da boa separação ocorrida entre os compostos polares e não voláteis, sem a necessidade de derivatização. Os métodos CLAE que utilizam a detecção UV são considerados os mais práticos devido à sua simplicidade e baixo custo (Scherer et al., 1998).

Dentre os métodos por CLAE encontrados na literatura, o de Ducos et al., publicado em 1990, vem sendo modificado por vários autores, mas continua a ser o método mais empregado na determinação do ATTM urinário. Este autor introduziu, na técnica de determinação do ATTM por CLAE, a etapa de purificação e extração prévia da urina em colunas preparatórias de troca iônica (SAX), condicionadas com água e metanol. Esta etapa analítica tornou as análises de ATTM urinário mais específicas e sensíveis, uma vez que inúmeras substâncias interferentes presentes na urina passaram a ser eliminadas durante a etapa de extração em fase sólida.

\section{MATERIAL E MÉTODOS}

Todos os reagentes utilizados foram de grau HPLC: $\operatorname{ATTM}\left(\right.$ Sigma $\left.^{\circledR}\right)$, metanol $\left(\right.$ Merck $\left.^{\circledR}\right)$ e ácido acético (Carlo $\left.\mathrm{Erba}^{\circledR}\right)$. As colunas preparativas de troca iônica contendo $100 \mathrm{mg}$ de fase sólida Bakerbond SPE ${ }^{\mathrm{TM}}$ foram da J. T. Baker $^{\circledR}$.

Partindo-se de uma solução padrão estoque de ATTM em metanol $(200 \mu \mathrm{g} / \mathrm{mL})$ foram preparadas soluções intermediárias em fase móvel (ácido acético 1\% metanol $(90-10 \mathrm{v} / \mathrm{v})$ em $\mathrm{pH}$ de 2,72$)$ nas concentrações 100,$00 ; 50,00 ; 25,00 ; 12,50$; e $3,12 \mu \mathrm{g} / \mathrm{mL}$, que foram utilizadas no preparo das soluções de trabalho.

As soluções de trabalho foram preparadas, também, em fase móvel nas concentrações 4,00; 2,00; 1,00; 0,50; 0,$06 ; 0,03$ e $0,01 \mu \mathrm{g} / \mathrm{mL}$.

Foi selecionado por sua simplicidade analítica, o método por CLAE proposto por Ducos et al., (1990). Algumas modificações foram realizadas no método original durante a etapa de validação analítica. A primeira delas foi a substituição da coluna cromatográfica por uma semelhante disponível no laboratório, a LiChrosorb RP18 (250 x 4,2 mm), $5 \mu \mathrm{m}$ da Merck $^{\circledR}$.

Outra modificação realizada foi no comprimento de onda (1) utilizado para detectar o ATTM. O 1 foi alterado 
de 259 para $264 \mathrm{~nm}$, uma vez que este último mostrou-se igualmente sensível na detecção do ATTM e menos eficiente na detecção do pico urinário interferente que elui da coluna cromatográfica próximo ao pico do ATTM.

O método original de Ducos et al. (1990) não faz referência ao uso de temperatura durante a análise por CLAE. Neste trabalho, entretanto, a coluna cromatográfica foi mantida à temperatura de $40^{\circ} \mathrm{C}$, o que resultou em melhor resolução dos picos cromatográficos.

Objetivando-se diminuir o custo das análises, foram testadas para a extração do ATTM, colunas preparativas de troca iônica (Bakerbond SPE ${ }^{\text {TM }}{ }^{\circledR}$ J.T.Baker ${ }^{\circledR}$ ) de $1 \mathrm{~mL}$ contendo $100 \mathrm{mg}$ de adsorvente. Como a quantidade de adsorvente contida nestas colunas era menor do que nas colunas utilizadas por Ducos et al. (1990), volumes menores de amostra e eluente foram usados. Com estas modificações, não foi necessário fazer a diluição do eluato final como proposto no método de Ducos et al. (1990) e o tempo de retenção do ATTM e o tempo total de corrida foram menores que os citados no trabalho original.

Este método consta das seguintes etapas:

(a) condicionar a coluna de troca iônica Bakerbond $\mathrm{SPE}^{\mathrm{TM}}{ }^{\mathrm{B}} \mathrm{com} 1,5 \mathrm{~mL}$ de metanol e $1,5 \mathrm{~mL}$ de água milli-Q,

(b) eluir pela coluna a amostra biológica $(250 \mu \mathrm{L}$ de urina $)$ com conseqüente adsorção do ATTM pelo amônio quaternário da coluna.

(c) lavar a coluna com $1 \mathrm{~mL}$ de solução de ácido acético a $1 \%$, para eliminar as impurezas (compostos com grupos funcionais carregados negativamente) que podem estar retidas no adsorvente.

(d) eluir o analito com $1 \mathrm{~mL}$ de ácido acético a $10 \%$ e injetar $20 \mathrm{~mL}$ do eluato no cromatógrafo.

As análises cromatográficas foram realizadas em cromatógrafo líquido de alta eficiência da Hewlett Parckard $^{\circledR}$ (HP) modelo 1100 , equipado com bomba isocrática, termostato, coluna cromatográfica ( $250 \times 4,2$ $\mathrm{mm})$ Lichrosorb RP 18, $5 \mu \mathrm{m}\left(\mathrm{MercK}^{\circledR}\right)$, detector de ultravioleta e ChemStation software.

A fase móvel utilizada foi uma solução aquosa de ácido acético 1\% - metanol (90-10 v/v), pH 2,72 em fluxo de $1,0 \mathrm{~mL} / \mathrm{min}$ ( pressão de 42 a 48 bar). A temperatura do termostato da coluna foi mantida a $40{ }^{\circ} \mathrm{C}$, o comprimento de onda $264 \mathrm{~nm}$ e o tempo total da corrida cromatográfica foi 16 minutos.

Foram estudados e estabelecidos os seguintes parâmetros analíticos: linearidade, limite de detecção do equipamento e limite de quantificação, interferência da matriz biológica, precisão e recuperação.

Após a validação analítica, o método otimizado foi aplicado em amostras de urina de trabalhadores expostos ao benzeno, objetivando confirmar a validade de seu uso na monitorização da exposição ocupacional ao solvente.

Foram coletadas 36 amostras de urina de indivíduos expostos ao benzeno em uma refinaria de petróleo da região metropolitana de Belo Horizonte no Estado de Minas Gerais. O nível de exposição ocupacional ao solvente de cada trabalhador foi determinado com o auxílio de monitores passivos individuais para compostos orgânicos voláteis (OVM-3500) dispostos ao nível da zona respiratória dos trabalhadores no dia da coleta da amostra biológica. Os indivíduos selecionados encontram-se na faixa etária de 18 a 50 anos $(34,8 \pm 8,7)$, sendo 26 do sexo masculino e 10 do sexo feminino.

Todas as amostras de urina foram coletadas ao final da jornada de trabalho, em frascos de plástico e transportadas para o laboratório em recipientes contendo gelo reciclado. As amostras que apresentaram valores de creatinina inferiores a $0,3 \mathrm{~g} / \mathrm{L}$ ou superiores a $3,0 \mathrm{~g} / \mathrm{L}$ não foram consideradas (Alessio et al., 1985). As urinas foram armazenadas, sem conservante, em nitrogênio líquido ($130^{\circ} \mathrm{C}$ ) até o momento da análise.

A análise do teor de creatinina nas amostras de urina foi realizada dentro de um prazo de 12 horas após a coleta, utilizando um "kit" colorimétrico de reação cinética $\left(\right.$ Labtest $\left.^{\mathbb{}}\right)$. Este método baseia-se na diferença das absorbâncias a $510 \mathrm{~nm}$ do cromógeno creatininapicrato, antes e depois da acidificação, medidos em um espectrofotômetro Shimadzu ${ }^{\circledR}$ UV 1601.

\section{RESULTADOS E DISCUSSÃO}

Nas condições cromatográficas estabelecidas, o tempo de retenção do ATTM apresentou valor médio de 6,66 minutos $\pm 0,07$ (Figura 1).

$\mathrm{O}$ estudo da linearidade do método foi realizado utilizando-se amostra biológica. Para isto, alíquotas de pool de urina, em quintuplicata, sem adição e adicionadas de ATTM nas concentrações de 10,$00 ; 5,00 ; 2,50 ; 1,00$; 0,$12 ; 0,06$ e $0,006 \mu \mathrm{g} / \mathrm{mL}$ foram submetidas ao método de extração anteriormente descrito.

A curva de linearidade foi feita utilizando-se a média dos valores das áreas dos picos de cada concentração de ATTM, subtraída a área média dos picos de ATTM obtidos após análise de pool de urina sem adição (ATTM basal).

A faixa de linearidade do ATTM nas condições analíticas foi de 0,006 a 10,000 $\mu \mathrm{g} / \mathrm{mL}$ (Figura 2).

O limite de detecção do equipamento (LDe), foi estabelecido como sendo a menor concentração de ATTM que apresentou, nas condições cromatográficas estabele- 


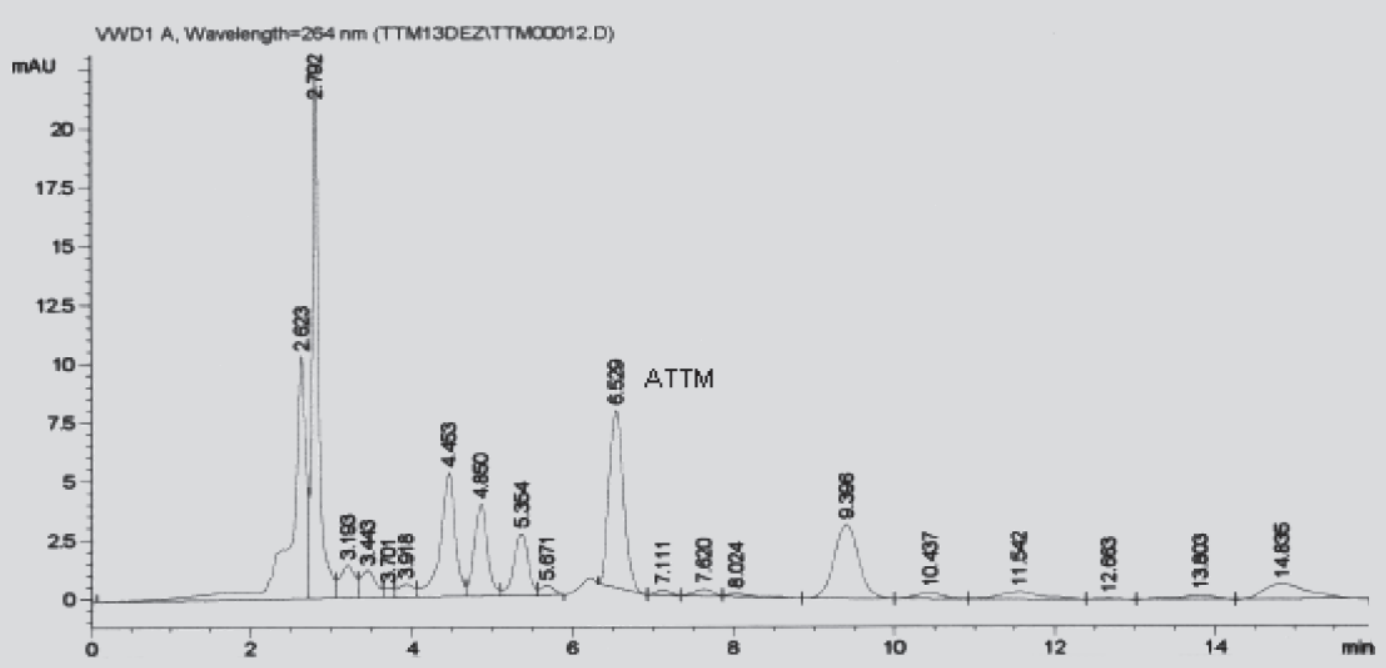

FIGURA 1 - Cromatograma obtido após análise de pool de urina adicionado de ATTM $(2,0 \mu \mathrm{g} / \mathrm{mL})$.

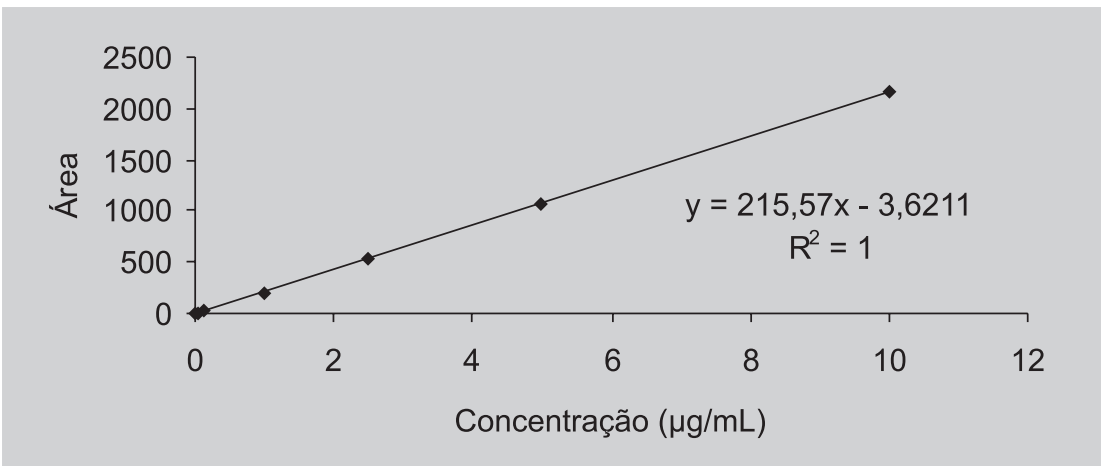

FIGURA 2 - Linearidade do ATTM nas condições analíticas otimizadas.

cidas, um pico cromatográfico homogêneo e integrado pelo detector, com uma variação igual ou menor que $20 \%$. Para isto, foram preparadas em quintuplicata, soluções de ATTM em fase móvel na faixa de concentração de 5,000 a $0,002 \mu \mathrm{g} / \mathrm{mL}$.

O valor encontrado para o LDe foi igual a $0,006 \mu \mathrm{g} / \mathrm{mL}$, valor adequado aos objetivos da monitorização.

A precisão do método analítico, expressa pelos coeficientes de variação $(\mathrm{CV})$ intra e interensaio é apresentada na Tabela I.

Para avaliar a precisão intra-ensaio do método analítico, 5 alíquotas de pool de urina adicionadas de ATTM, nas concentrações de 0,06 e $4,00 \mu \mathrm{g} / \mathrm{mL}$, foram analisadas em um mesmo dia. Para o estudo da precisão interensaio foram analisadas alíquotas de cada concentração, em quintuplicata, durante cinco dias consecutivos.
TABELA I - Coeficientes de variação intra e interensaio obtidos na determinação do ácido trans, trans-mucônico (ATTM)

\begin{tabular}{lcc}
\hline ATTM $(\mu \mathrm{g} / \mathrm{mL})$ & $\mathrm{CV}_{\text {intra-ensaio }}(\%)$ & $\mathrm{CV}_{\text {interensaio }}(\%)$ \\
\hline 0,06 & 15,05 & 15,40 \\
4,00 & 4,08 & 6,89 \\
Média & 9,57 & 11,15 \\
\hline
\end{tabular}

O estudo da interferência da matriz biológica sobre a concentração do ATTM foi realizado comparando-se as curvas de calibração construídas em água e urina nas concentrações 4,$00 ; 2,00 ; 0,50 ; 0,10$ e $0,06 \mu \mathrm{g} / \mathrm{mL}$ (quintuplicata) (Figura 3). Observou-se que os coeficientes angulares das equações das retas eram diferentes, caracterizan- 
do-se a existência do efeito matriz e, portanto, as quantificações do ATTM urinário foram realizadas com o auxílio de curvas de calibração confeccionadas com soluções padrão de ATTM preparadas em urina.

Para avaliar a recuperação do método analítico, foram analisadas cinco alíquotas de pool de urina, adicionadas de solução padrão de ATTM nas concentrações de 4,0; 2,0 e $0,1 \mu \mathrm{g} / \mathrm{mL}$. Paralelamente, alíquotas do pool de urina sem adição de ATTM foram igualmente extraídas, também em quintuplicata. A estes extratos foi adicionado
ATTM de modo a se obter as mesmas concentrações de 4,$0 ; 2,0$ e $0,1 \mu \mathrm{g} / \mathrm{mL}$.

A porcentagem de recuperação do método foi estabelecida comparando-se as concentrações de ATTM obtidas através dos procedimentos descritos acima.

Os resultados obtidos estão demonstrados na Tabela II e indicam adequada recuperação analítica.

Na Figura 4 está representada a curva de calibração construída em urina para o ATTM, de acordo com o método validado no presente trabalho.

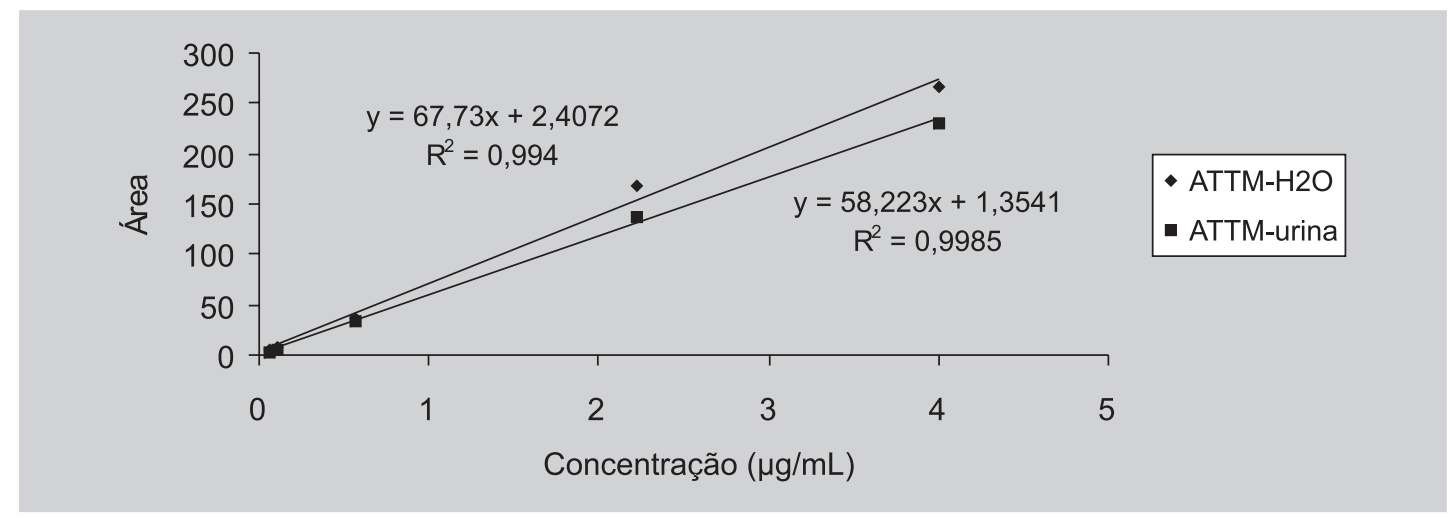

FIGURA 3 - Interferência da matriz biológica na determinação do ácido trans,trans-mucônico.

TABELA II - Porcentagem de recuperação do método analítico de determinação do ácido trans,trans-mucônico (ATTM) urinário

\begin{tabular}{cccc}
\hline ATTM $(\mu \mathrm{g} / \mathrm{mL})$ & $\begin{array}{c}\text { Concentração }{ }^{*} \\
\text { (adição após extração) }\end{array}$ & $\begin{array}{c}\text { Concentração 2* } \\
\text { (adição antes extração) }\end{array}$ & $\begin{array}{c}\text { Recuperação } \\
(\%)\end{array}$ \\
\hline 4,0 & 3,94 & 3,42 & 86,80 \\
2,0 & 2,15 & 1,84 & 85,58 \\
0,1 & 0,23 & 0,20 & 86,96 \\
\hline Média & & 86,45 \\
\hline
\end{tabular}

*média de 5 alíquotas analisadas

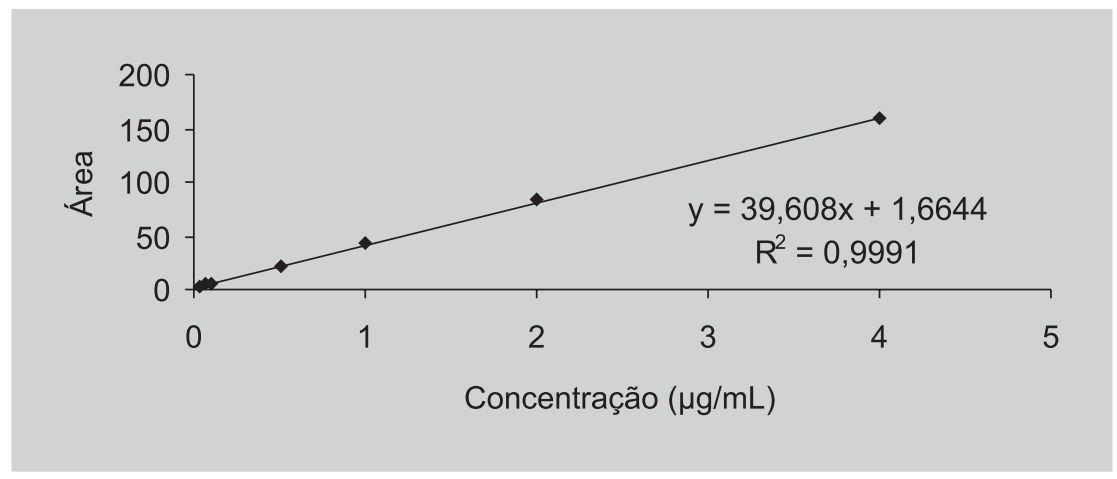

FIGURA 4 - Curva de calibração do ATTM urinário. 
Após a construção da curva de calibração, foi estabelecido o limite de quantificação do método, considerado como sendo a menor concentração de ATTM na curva de calibração, que apresentou uma variação igual à estabelecida para o método $(15,4 \%)$. O limite de quantificação do ATTM em urina foi igual a $0,03 \mu \mathrm{g} / \mathrm{mL}$.

$\mathrm{O}$ método validado acima foi aplicado a algumas amostras de urina de trabalhadores expostos ao benzeno. Os resultados analíticos foram corrigidos pela concentração de creatinina urinária e estão expressos na Tabela III.

TABELA III - Valores de benzeno no ar ocupacional e de ácido trans, trans-mucônico em amostras de urina de indivíduos expostos ao solvente submetidas ao método de análise validado

\begin{tabular}{cc}
\hline Valores & ATTM urinário $(\mathrm{mg} / \mathrm{g}$ creatinina) \\
\hline $\mathrm{n}$ & 36 \\
Média $\pm \mathrm{IC}$ & $0,19 \pm 0,04$ \\
$\mathrm{MG} \pm \mathrm{DP}$ & $0,16 \pm 0,12$ \\
Mediana & 0,16 \\
Valor mín & 0,04 \\
Valor máx & 0,67 \\
\hline
\end{tabular}

IC - intervalo de confiança a 95\%, MG - média geométrica; DP - desvio padrão

\section{CONCLUSÕES}

O método de Ducos et al. (1990), modificado e validado neste trabalho, mostrou-se sensível para a determinação da concentração urinária de ATTM em níveis tão baixos quanto $0,04 \mathrm{mg} / \mathrm{g}$ de creatinina, ou seja, dentro da faixa de referência do biomarcador.

As modificações introduzidas no método original possibilitaram diminuir o tempo da análise cromatográfica e o gasto de reagentes químicos do método. Vantagens significativas em uma rotina laboratorial, especialmente quando análises referentes à monitorização biológica de exposições ocupacionais estão sendo realizadas.

Linearidade, sensibilidade e porcentagem de recuperação do método validado mantiveram-se semelhantes às do método original, embora tenha sido observada diminuição aceitável na precisão analítica, decorrente, provavelmente, da inexistência da automação durante a fase de extração em fase sólida nas colunas preparativas.

O método de Ducos et al., 1990, modificado e validado no presente trabalho, mostrou-se adequado para ser utilizado na monitorização biológica da exposição ocupacional ao benzeno, utilizando-se o ácido trans, transmucônico urinário como biomarcador .

\section{ABSTRACT \\ Validation of modified Ducos's method for the determination of urine trans,trans-muconic acid}

This work was conducted in an attempt to validate a method for determination of trans, trans-muconic acid (TTMA) by high performance liquid chromatography with UV detection. The clean-up procedure of samples involves the use of strong anionic exchange cartridges for solid phase extraction. Purified samples are injected onto a reversed phase column Lichrosorb RP $18(250 \times 4.2 \mathrm{~mm}-5 \mu \mathrm{m})$ temperature of $40^{\circ} \mathrm{C}$. The isocratic run is performed at a constant flow of $1.0 \mathrm{~mL} / \mathrm{min}$; the mobile phase consists of acetic acid 1\% and methanol (90:10 v/v) pH 2.72 and the $U V$ detector is set at $264 \mathrm{~nm}$. The analytic validation results were in the linearity range of $0.006-10.0 \mu \mathrm{g} / \mathrm{mL}$, detection and quantification limits of $0.006 \mu \mathrm{g} / \mathrm{mL}$ and $0.03 \mu \mathrm{g} / \mathrm{mL}$ respectively, intra and interassay coefficient of variation $9.57 \%$ and $11.15 \%$ respectively and recovery of $86.42 \%$. The method seems suitable for biological monitoring of subjects exposed to benzene.

UNITERMS: Trans,trans-muconic acid. Benzene. Validation. HPLC. Biomonitoring.

\section{AGRADECIMENTOS}

À FAPEMIG (Fundação de Amparo à Pesquisa do Estado de Minas Gerais) e CNPq/PRPq-UFMG (Conselho Nacional de Desenvolvimento Científico e Tecnológico) pelo apoio financeiro no desenvolvimento desta pesquisa.

\section{REFERÊNCIAS BIBLIOGRÁFICAS}

AMERICAN CONFERENCE OF GOVERNMENTAL INDUSTRIAL HYGIENISTS. Threshold limit values for chemical substances and physical agents and biological exposure índices -1998-1999. Cincinnati: ACGIH, 1999. 48 p.

ALESSIO, L.; BERLIN, A.; TOFFOLETTO, F.; GHEZZI, I. Reability of urinary creatinine as a parameter used to adjust of urinary biological indicators. Int. Arch. Occup. Environ. Health, Berlin, v. 55, p.99-106, 1985.

BECHTOLD, W.E.; SUN, J.D.; BIRNBAUM, L.S.; YIN, S.N.; LI, G.L.; KASICKI, S.; LUCIER, G.; HENDERSON, R.F. S-phenylcysteine formation in hemoglobin as a biological exposure index to benzene. Arch. Toxicol., Berlin, v. 66, n.5, p. 303-309, 1992. 
BECHTOLD, W. E.; HENDERSON, R. F. Biomarkers of human exposure to benzene. J. Toxicol. Environ. Health, London, v.40, p.377-386, 1993.

BECHTOLD, W. E.; STRUNK, M. R. S-phenylcysteine in albumin as a benzene biomarker. Environ. Health Perspect., Washington, v.104, suppl. 6, p. 1147-1149, 1996.

BOOGAARD, P. J.; VAN SITTER, N. J. Biological monitoring of exposure benzene: a comparison between S-phenylmercapturic acid, trans-trans muconic acid and phenol. Occup. Environ. Med., London, v.52, n.9, p.611620, 1995.

BOOGARD, P. J. ; VAN SITTER, N. J. Suitability of S-pheyl mercapturic acid and trans-trans-muconic acid as biomarkers for exposure to low concentrations of benzene. Environ. Health Perspect., Washington, v. 104, n. 6, p. 1151-1157, 1996.

BRASIL. Ministério do Trabalho. Secretaria de Relações do Trabalho. Portaria n ${ }^{\circ} 24$, de 29 dez. 1994. Diário Oficial, Brasília, 30 dez. 1994. Seção 1, p. 21278-21279.

BRASIL. Ministério do Trabalho e Emprego. Portaria n 34 , de 20 dez. 2001. Diário Oficial, Brasília, 27 de dez. de 2001.p. 260-261.

DUCOS, P.; GAUDIN, R.; ROBERT, A.; FRANCIN, J. M.; MEIRE, C. Improvement in HPLC analysis of urinary trans, trans muconic acid,a promissing substitute for phenol in assessment of benzene exposure. Int. Arch. Occup. Environ. Health, Berlin, v.62, p.529-534, 1990.

GAD-EL KARIM, M. M.; RAMANUJAM, V. M. S.; LEGATOR, M. S. Trans, trans-muconic acid, an openchain urinary metabolite of benzene in mice. Quantification by high-pressure liquid chromatography. Xenobiotica, London, v.15, p.211-220, 1985.

GOBBA, F.; ROVESTI, S.; BORELLA, P.; VIVOLI, R.; CASELGRANDI, E.; VIVOLI, G. Inter-individual variability of benzene metabolism to trans, trans muconic acid and its implications in the biological monitoring of ocupacional exposure. Sci. Total Environ., Amsterdam, v. 199, p. 41-48, 1997.
MELIKIAN, A. A.; PRAHALAD, A. K.; HOFFMANN, D. Urinary trans,trans-muconic acid as na indicator of exposure to benzene in cigarette smokers. Cancer Epidemiol. Biomarkers Prev., Philadelphia, v.2, p.47-51, 1993.

MELIKIAN, A. A.; PRAHALAD, A. K.; SECKERWALKER, R. H. Comparison of the levels of the urinary benzene metabolite trans-trans muconic acid in smokers ans nonsmokers, and the effects of pregnancy. Cancer Epidemiol. Biomarkers Prev., Philadelphia, v.3, n.3, p.239-244, 1996.

KIVISTÖ, H.; PEKARI，K.; PELTONEN， K.; SVINHUFVUD, J.; VEIDEBAUM, T.; SORSA, M.; AITIO, A. Biological monitoring of exposure to benzene in the production of benzene and in a cokery. Sci. Total Environ., Amsterdam, v. 199, n.1-2, p. 49-63, 1997.

LAUWERYS, R. R.; BUCHET, J. P.; ANDRIEN, F. Muconic acid in urine: a reliable indicator of occupational exposure to benzene. Am. J. Ind. Med., New York, v. 25, p. 297-300, 1994.

OGA, S. Fundamentos de Toxicologia. São Paulo: Atheneu Editora Ltda, 1996. p. 193-197.

ONG, C. N.; KOK, P. W.; LEE, B. L.; SHI, C. Y.; ONG, H. Y.; CHIA, K. S.; LEE, C. S.; LUO, X. W. Evaluation of biomarkers for occupational exposure to benzene. Occup. Environ. Med., London, v. 52, n.8, p.528-533, 1995.

RAUSCHER, D.; LEHNERT, G.; ANGERER, J. Biomonitoring of occupational and environmental exposures to benzene by measuring trans, trans-muconic acid in urine. Clin. Chem., New York, v.40, p.1468-1470, 1994.

SCHERER, G.; RENNER, T.; MEGER, M. Analysis and evaluation of trans, trans - muconic acid as a biomarker for benzene exposure. J. Cromatogr. B, Amsterdam, v. 717, p. 179-199, 1998.

Recebido para publicação em 24 de abril de 2002. 